\title{
Changing Work Environment through Information and Communication Technology (ICT): Challenges to Secretarial Staff
}

\author{
Ayandele, I. A \\ Department of Business \\ Management \\ University of Uyo, Uyo
}

\author{
Adeoye O. S. \\ Department of Computer Science \\ University of Uyo, Uyo
}

\begin{abstract}
Computer technology is fast becoming a vital engine of growth for the world's economy. It has created opportunities for many enterprising individuals, firms and communities globally. Likewise, it has altered the very nature of organizational work and is about to change the work itself. While typewriters are disappearing in favour of word Processors, office vernaculars are also polarized with different acronyms and terminologies in ICT. This paper observes that since computer literacy is already a prerequisite for employment and career mobility. It is therefore, expedient that everybody, and especially secretarial staff should be ICT compliant.
\end{abstract}

Keywords: Changing work environment, ICT, office automation system, information system, cyberphobia, videoconferencing.

\section{INTRODUCTION}

Man is truly an amazing being: he is a master of inventions. He is restless by nature; either his desire to make things easier and sophisticated or his game loving nature drives his imaginations to keep inventing. The wheel, the television or the vehicles we see on the roads, are some of the inventions of man that we cannot imagine our lives without today. The computer system is also in the list of amazing man's inventions. The computer made its first appearance somewhere in the late 19th century but started getting popular only in the 20th century. Today it has become a part and parcel of almost everybody's life.

There is hardly a sphere of live, which has not in some ways been affected by the computer. We have seen the influence of computer in manufacturing, commerce, education, banking, home, military; religion etc. The computer has affected our lives and society both in positive and -negative ways. The world is currently undergoing revolution in automation, which is rightly referred to as the 'digital revolution'. The revolution is already transforming social and economic life and is moving at near lightning speed. Computer Technology is one of the most potent forces shaping the 21 st century. It is fast becoming a vital engine of growth for the world's economy, creating opportunities for many enterprising individuals, firms and communities globally.

Successful organizations have recognized that computer and communication technology have fundamentally alter the very nature of organizational work; who can do it? Where and when can it be done? This change in turn often requires the rethinking of the strategy of the organization with a subsequent remaking of its basic structure and processes. The precise form of the organizational change and the opportunities to be seized are contingent upon the extent to which scale, scope and network economies are present, but in all cases success at the corporate level requires costly and time consuming organizational transformation.

Although this paper focuses in depth on a single case of information and communication technology (ICT) on one hand and related transformations in secretarial activities on the other hand, our conclusions are quite general.

\section{THEORETICAL BACKGROUND}

An information system is an organized combination of people, hardware, software, communications network and data resources that collect, transforms and disseminates information in an organization [9]. Information Technology has also been defined as the use of electronic equipment, especially the computer for the storage, analysis and disseminating of information [7]. Information and Communication Technology (ICT) is the use of electromechanical equipments like the computer, telephone, internet and other gadgets for the collection, analysis, processing, storage and retrieving of data / information for the attainment of a particular objective(s) in all aspects of life [10]. From the above, it can be observed that the computer/computer network plays a central role in the design and operation of any formation of Information and Communication Technology.

People have relied on information systems to communicate with each other using a variety of physical devices (hardware), information processing instructions (software), communications channels (networks) and stored data (data resources) since the dawn of civilization. Information systems play a vital role in the business success of any enterprise [2]. It provides the information a business needs for efficient operations, effective management, and competitive advantage. However, if information systems do not properly support the strategic objectives, business operations, or management needs of an enterprise, they can seriously damage its prospects for survival and success. So, the proper management of information systems is a major challenge for managers. 


\section{GLOBAL INFORMATION SOCIETY}

Information is a basic resource in today's society [9]. We are living in a global information society, with a global economy that is increasingly dependent on the creation, management, and distribution of information resources. People in many nations no longer live in agricultural societies, composed primarily of farmers, or even industrial societies, where a majority of the workforce consists of factory workers. Instead, the workforce in many nations consists primarily of workers in services occupations or knowledge workers, that is, people who spend most of their workday creating, using and distributing information.

Knowledge workers include executives, managers, and supervisors; professionals such as accountants, engineers, scientists, stockbrokers, and teachers; and staff personnel such as secretaries and clerical office personnel. Most of them are end users who make their living using information systems to create, distribute, manage and use information resources. Thus, information systems help them manage the human, financial, material, energy, and other resources involved in their work responsibilities.

Information and information systems then are valuable resources for knowledge workers, their organizations, and society. A major challenge for our global information society is how to manage its information resources to benefit all members of the society while meeting the strategic goals of organizations and nations [1]. This means, for example, using information systems to find more efficient, profitable and socially responsible ways of using the world's limited supplies of material, energy and other resources. Since the information systems of so many organizations are interconnected by local, regional and global telecommunications network, knowledge workers can now access and distribute information and manage resources all over the world with no or little difficulties [4].

\section{TECHNOLOGICAL AND BEHAVIORAL DIMENSIONS OF INFORMATION AND COMMUNICATION TECHNOLOGY (ICT)}

Computer Science, Engineering, and Mathematics are disciplines that contribute to the technological aspects of information systems in business [9]. These disciplines along with the information systems discipline drive developments in computer hardware, software, telecommunications, database management, and other information technologies. On the other hand, areas such as psychology, sociology, and political science contribute to the behavioral aspects of information systems in organizations. The research findings of these behavioral disciplines and the discipline of information systems shed light on how individuals and organizations can effectively use and manage information technology.

For example, research in psychology and sociology helps in the design of information and communication technologies, which support individual and group communications, decision-making, and cooperative work. Some of the research findings drawn from Political Science, on the other hand, focuses on the politics and governance issues involved in managing the introduction and the use of Information and Communication Technology in organizations [5].

Both of these aspects, the technological and behavioral, are therefore, important for businesses and other end users of information systems. That is because computer-based information systems, though heavily dependent on information and communication technologies are designed, operated and used by people in a variety of organizational settings. Thus, the success of an information system should not be measured only by its efficiency in terms of minimizing costs, time, and the use of information resources. Success should also be measured by the effectiveness of the information technology in supporting and meeting the goals of end users, their work group and organizations.

\section{CHANGING WORK ENVIRONMENT VIA INFORMATION AND COMMUNICATION TECHNOLOGY (ICT)}

From the day the computer moved from the mainframe to the mainstream, it had been assumed that the introduction of Information and Communication Technology (ICT) would make office work more interesting and more productive. Typewriters are disappearing in favour of word processors, spreadsheets replaced calculators, and office vernacular became polarized with acronyms and terminologies like Joy-stick, logging, cyberphobia, telecommuting, teleconferencing, telemedicine, videoconferencing, web-site, www.com etc. The way organizations operate, if not the actual work, has changed and surely for the better.

ICT has changed the equipment and work groups, of course; nobody today would like to work in an office where information processing and other secretarial activities are done manually or mechanically. So, the mechanized office is gradually given way to the automated office. Investment in networks of computerbased workstations and other automated equipment is transforming traditional Manual office methods and paper communications media. This transformation has resulted in the development of automated systems that rely on electronic collaboration and communication networks, text processing, image processing and other information and communication technologies.

\section{COMPARATIVE ANALYSIS OF THE OLD AND THE NEW ORDER: CHALLENGES TO SECRETARIAL STAFF}

Before now, it was a common phenomenon to see heaps of used and unused file folders, calendars and almanacs, appointment note books/dairies, telephone directories, memo pads, dispatch books, inventory records, file cabinets, legion of office assistants (for mail deliveries), etc in a typical Nigerian office. Also, it was common in our offices to hear that, the Secretary or a particular secretarial staff is on leave, has traveled to attend a seminar, 
workshop or is attending a meeting and therefore, the office machinery (work) is grounded till the individual physically resumes back to work.

It was also very common to hear that a mail sent out a week ago is yet to be delivered (still in transit). Or a mail is missing in transit and could not even be traced. Also common, is a situation where the telephones of executives are perpetually busy making it difficult for calls (even emergency) to sail through.

Today, the Information and Communication Technology revolution has dramatically changed all these and is moving quickly towards changing the work itself. The following are the modern ICT devices found in most offices for secretarial functions. They are, electronic computers with modern office accessories or packages and internet facilities for on-line communication and collaboration, computer printers, plotters, digit-memo, fax machine, photo-copier, Digital video camera, close circuit television, large-screen video projector, etc. Similarly, the days of relying primarily on ICT professionals to meet our information processing needs are over. Today's secretarial staff are expected to use net-worked microcomputers as professional workstations to acquire the information they need to accomplish their jobs successfully.

The scope of ICT is a very wide one that covers office automation, transaction processing, management reporting, decision support system, ICT for strategic competitive advantage, etc. This paper however, restricts itself to office automation concepts and practices depicting what are expected of a modern office or secretariat.

\section{OFFICE AUTOMATION}

Office automation has been viewed as telecommunication-based information systems that collect, process, store, and distribute electronic messages, documents and other forms of communications among individual work groups and organizations [8]. Such systems can improve the collaboration and productivity of secretarial staff and work groups by significantly reducing the time and efforts needed to produce, distribute, and share office information [3].

One way people interact is by meeting together. Equipping conference rooms therefore, with computers and sophisticated software can support such meetings. Alternatively, videoconferencing and desktop-conferencing enable people to meet without physically moving. Another way people interact is by speaking, which computers support with voice mail and voice annotation. People also interact by writing, supported by collaborative writing tools and electronic mail (e-mail) applications.

The entire (scope) office automation system comprises the following five (5) sub systems:

- $\quad$ Electronic Publishing Systems

- $\quad$ Electronic Communications Systems

- $\quad$ Electronic Collaboration Systems

- $\quad$ Image Processing System

- Office Management Systems

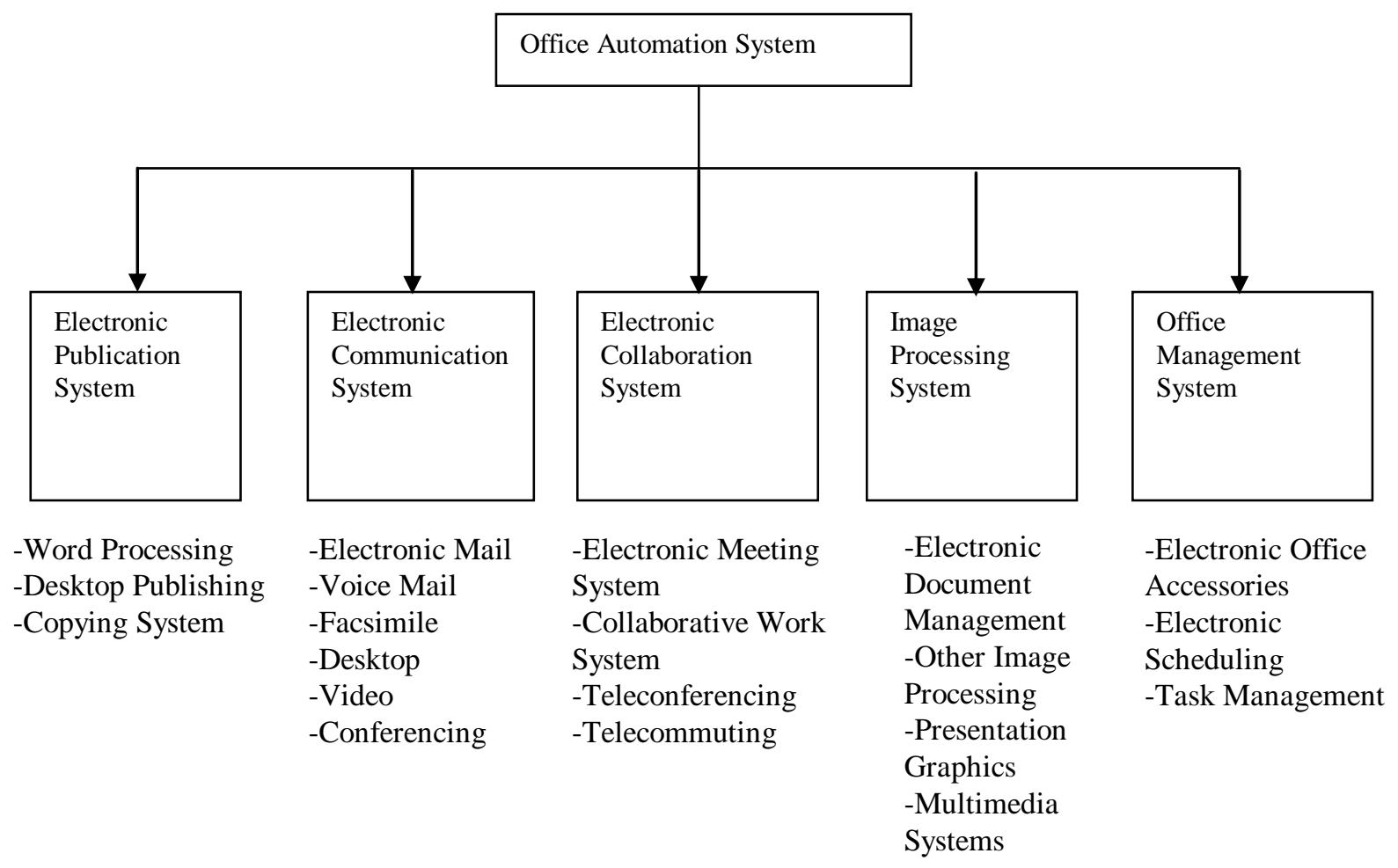

Fig 1: An overview of office automation system. Source [9] 


\subsection{Electronic Publishing Systems}

Electronic publishing systems have transformed today's office into an in-house publisher of office documents. Word Processing and Desktop Publishing are the information technologies that give the modern workplace electronic publishing capabilities. Word Processing is the use of computer systems to create, edit, revise and print text materials. Word processing involves manipulating Text Data (characters, words, sentences, and paragraphs) to produce information products in the form of documents (letters, memos, forms and reports). With Desktop Publishing, organizations can design and print their own newsletter, brochures, manuals and books with several type styles, graphics and colors on each page.

\subsection{Electronic Communications Systems}

These are central nervous systems of today's organizations. Electronic mail (e-mail), voice mail, bulletin board systems, and facsimile allow organization to send messages in text, video, or voice form or transmit copies of document and to receive it in seconds, not hours or days. Such systems transmit and distribute text and images in electronic form over telecommunications networks. This enhances the communications and coordination among work groups and organizations. Electronic communications systems help reduce the flow of paper messages, letters, memos, documents, and reports that floods our present secretariats or offices and postal systems.

\subsubsection{Electronic Mail}

Millions of end users now depend on electronic mail (e-mail) to send and receive electronic messages. You can send e-mail to anyone on your network for storage in his/her electronic mail boxes or magnetic disk drives. Whenever they are ready, they can read their electronic mail by displaying it on the video screens at their workstations. So, with only a few minutes of effort (and a microseconds of transmission), a message to one or many individuals can be composed, sent, and received.

\subsubsection{Voice Mail}

This is also called Voice Store-and-Forward. Here, digitized voice messages, rather than electronic text, are used. In this method, you first dial the number of the voice mail service. In some secure systems, you may be asked to enter an identification code. Once you are accepted, you dial the voice mail number of the person you wish to contact and speak your message. Your analog message is digitized and stored on the magnetic disk devices of the voice mail computer system. Whenever you want to hear your voice mail, you simply dial your mailbox and listen to the stored messages, which the computer converts back into analog voice form.

\subsubsection{Bulletin Board Systems}

(BBS): They are a popular telecommunications services provided by the internet, public information services, and thousands of business firms, organization, and end user groups. An electronic bulletin board system allows you to post public or private messages that other end users can read by accessing the BBS with their computers. Establishing a small BBS for a business is not that difficult. Minimum requirements are a microcomputer with a hard disk drive, custom or packaged BBS software, modem and a telephone line.

Bulletin Board System serves as a central location to post and pick up messages or upload and download data files or programs 24hours a day. A BBS helps end users ask questions, get advice, locate and share information, and get in touch with other end users.

\subsubsection{Facsimile (Fax)}

This is not a new office telecommunications services. However, advances in digital imaging technology and microelectronics have caused a sharp drop in prices and a significant increase in capabilities.

Facsimile allows you to transmit images of important documents over telephone or other telecommunication links. Thus, longdistance copying might be an appropriate nickname for this telecommunications process. Usually, a fax machine at another location, with both units connected to high-speed modems is required. Transmission speeds for digital office fax machines range from one to four pages per minute, with quality equivalent to an office copier. However, facsimile circuit boards and fax modems are also available for microcomputers. Installing a fax board or fax modems and using a fax software package allows a personal computer to transmit copies of words processing, spread sheet, and other files to fax machines anywhere. Thus, fax machines can now become remote dial-up printers for microcomputer systems.

\subsubsection{Desktop Videoconferencing}

Here participants at remote sites key in their presentations and responses whenever convenient from their online terminals or workstations connected to a central conference computer.

\subsection{Electronic Collaboration Systems}

These systems cover the following:

\subsubsection{Electronic Meeting Systems}

Why do people have to spend travel time and money to attend meetings away from their normal work locations? They do not have to if they use several types of Electronic Meeting Systems (EMS), a growing method of electronic office telecommunications. Electronic meeting systems involve the use of video and audio communications to allow conference and meeting to be held with participants who may be scattered across a room, a building, a country, or the globe. Reducing the need to travel to and from meetings should save employee time, increase 
productivity, and reduce travel expenses and energy consumption.

\subsubsection{Major Categories of Electronic Meeting Systems}

\subsubsection{Computer Conferencing}

This involves using an online terminals and workstations to conduct conference among participants at remote sites over a period of time, without the use of interactive video.

\subsubsection{Desktop Videoconferencing}

This is using appropriately equipped end-user workstations to hold two-way interactive video conferencing.

\subsubsection{Teleconferencing}

This involves using interactive video telecommunications to hold conferences among many participants at remote site.

\subsubsection{Decision Room Conferencing}

It involves using a meeting room with a network of workstations and large-screen video projection to hold meetings.

\subsubsection{Telecommuting}

This is the use of telecommunications by workers to replace commuting to work from their homes. It is also used to describe the use of telecommunications to carry on work activities from temporary locations other than offices and homes. Some people refer to telecommuting as the creation of VIRTUAL OFFICES. Workers use a computer terminal or microcomputer with telecommunications capability to access their company's computer network and database. Telecommuting workers and their colleagues also use electronic mail or voice mail to communicate with each other about job assignments. It is especially helpful for handicapped persons and working parents of young children.

Telecommuting is becoming a significant work alternative at major corporations and a common approach for many independent professionals. It seems to be most attractive to people whose jobs involve a lot of individual work, such as programmers, systems analysts, writers, consultants, and so on.

\subsection{Image Processing System}

This is another fast-growing area of office automation. It allows end users to electronically capture, store, process, and retrieve images of documents that may include numeric data, text, handwriting, graphics, and photographs. Electronic document management may interface with other electronic document preparation systems such as word processing, desktop publishing, electronic mail, and voice mail. However, one of the fastest growing application areas is Transaction Document Image
Processing. Document such as customer correspondence, sales orders, invoice, application forms, and service request are captured electronically (scanned) and routed to end users throughout the organization for processing.

\subsubsection{Presentation Graphics}

The goal of presentation graphics is to provide information in a graphical form that helps end users and managers understand business proposals and performance and make better decisions about them. This includes the use of line and bar graphics, pie charts and pictorial charts using a variety of symbols. Instead of being overwhelmed by large amounts of computer-produced data, graphic displays can assist mangers in analyzing and interpreting information presented to them. Presentation graphics does not totally replace reports and displays of number and text materials.

\subsubsection{Multimedia Presentation}

Multimedia methods of presentation give end users information in a variety of media, including methods text, and graphics displays, voice and other digitized audio, photographs, and video clips.

\subsection{Office Management Systems}

They include electronic calendars, electronic mail directories, schedulers, and task management systems. They provide computer-based support services to managers and other professionals to help them organize their work activities. Office management software computerizes manual methods of planning such paper calendars, appointment books, directories, file folders, memos, and notes. Microcomputer users can get some of the benefits of office management systems by using Desktop Accessory and Personal Information Manager Packages.

-For example, you could enter the data and time of a meeting into an electronic calendar.

-An electronic tickler file will automatically remind you of important events.

-Electronic scheduler use the electronic calendars of several people to help you schedule meetings and other activities with them.

-Desktop accessories provide features such as calculator, notepad, alarm clock, phone directory, and appointment book that pop-up in a window on the display screen to your workstation at the touch of a key.

-Electronic mail directories help you contact people easily. 
-Electronic task management packages help you plan a series of related activities so that scheduled results are accomplished on time.

\section{CONCLUSION AND RECOMMENDATIONS}

Concern about the effects of office automation or automation generally began with the industrial revolution, and the public is still much afraid. To many people, computer means automation, and automation means loss of jobs. There is no doubt however, that the emergency of Computer and Information Technology has resulted in the elimination of jobs involving routine, monotonous and sometimes hazardous tasks.

However, the loss of these jobs has often been offset by the creation of more challenging ones. Many people whose jobs have been eliminated have been displaced to jobs carrying greater responsibilities and offering more opportunities.

For instance, it is common nowadays, for book-keepers to become system analysts, for draughts-men to advance to Computer-Aided-Designers, and for secretarial staff (Secretaries) to become specialist in a myriad of computer applications like word processing, system analysis, graphic designing, programming and data management.

It is very obvious, therefore, that automation will continue to eliminate and create new jobs. With the cost of labour increasing and the cost of computers decreasing, the trend towards the automation of routine activities will definitely continue. Already, computer literacy is a prerequisite for employment in some professions. Similarly, career mobility has become intertwined with an individual's current and future knowledge of information and Communication Technology (ICT). Therefore, a secretarial staff without computer knowledge will soon be out of job. Such people will discover that the world has left them behind.

However, to realize smooth transition to an automated office environment, organizations (public or private) must recognize that they have a social responsibility to re-train those who will be displaced by the loss of their jobs due to the impact of Information and Communication Technology (ICT). Secondly, employers should consistently equip their organizations with modern ICT facilities. Finally, the government should improve our epileptic power supply for smooth flow of ICT operations.

\section{REFERENCES}

[1] Baily, M. N (2004), Recent Productivity Growth: The Role of Information Technology and other Innovations' Federal Reserve Bank of San Franciso Economic Review.

[2] Basu, S. Fernald, J.G. Outon, N. and Srinivasan, S. (2003), 'The case of The Missing Productivity Growth: Or Does Information Technology Explain Why Productivity Accelerated in the United State but not in the United Kingdom? Federal Reserve Bank of Chicago Working Paper, No. 8
[3] Black, S. E. and Lynch, L. M. (2004) What's Driving the New Economy? The Benefits of Workforce Innovation, Economic Journal Vol. 114.

[4] Boyer, R. (2005), The Future of Economic Growth, Cheltenham: Edward Elger.

[5] Carr, N. G. (2005), 'The End of Corporate Computing,' MIT Solan Management Review Spring.

[6] Fapohunda A. (1995) Understanding and Using Microcomputers. Abuja, Aflon Limited

[7] Howells, J. and Tether, B. (2004), Innovation in Services: Issues at Stake and Trends Commission of the European Communities Brussels - Luxembourg.

[8] Laudon K. C and Laudon J. P (1995) Essentials of Management Information Systems, New York, Prentice Hall.

[9] O’ Brien, J. A (1996) Management Information Systems (3rd ed.), Boston, Richard Irwin.

[10] Van-Art, B, Inklaar, R. and M. Guckin, R. H. (2002), "Changing Gear" Productivity, ICT and Service Industries: Europe and the United States; Research Memorandum G D-60 Groningen Growth and Development Centre, University of Groningen. 